
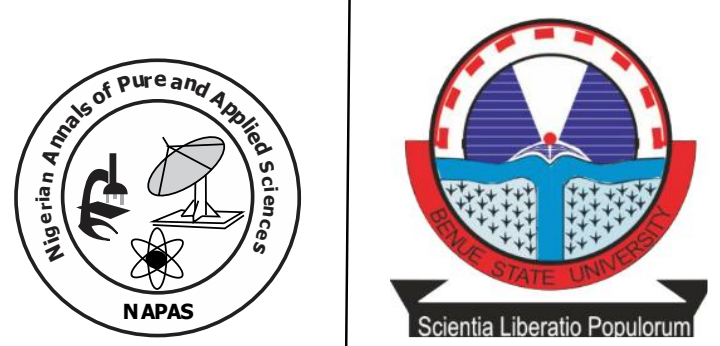

\title{
Estimating the Proportion of Alcohol, Illicit Substance and Drug Users and Impacts on Project Performance in Construction Sites in Adamawa and Taraba State, North Eastern Nigeria.
}

\author{
Jibesen, D. ${ }^{1}$ Haruna, A.C. ${ }^{2}$ and Yamusa, I.R. ${ }^{3}$ \\ University of Technology, Yola \\ djibasen@mautech.edu.ng \\ 2Department of Building, \\ Modibbo Adama University of Technology, Yola \\ amoschom@mautech.edu.ng \\ ${ }^{3}$ Council of Registered Builders of Nigeria, \\ Federal Secretariat Complex, Yola \\ irisimrita@corbon.gov.ng
}

1Department of Statistics and Operations Research Modibbo Adama

\begin{abstract}
This study used the Respondent Driven Sampling (RDS) method to estimate the proportion of alcohol Illicit Drug and Substance Users amongst Construction Sites workers in Adamawa and Taraba States of Nigeria. 26 seeds (initial recruits) were selected via convenience sampling from 26 construction sites in the two States with 13 from each state. 330 coupons were distributed to each of the states, making a total of 660 recruits. A behavioural questionnaire was administered on the recruits through the site's managers. The RDSAT 7.1 software was used for the analysis, taking into account their network sizes and homophily values, while Net-draw was used for graphing the recruitment chains. The result shows that RDS is a reliable means as out of the 660(100\%) targeted sample size of recruits, 623(94\%) were successfully recruited. Results further revealed that, in both states, artisans of age less than 30 are mostly involved in drug abuse and that carpenters who engaged in drugs/substance/alcohol used incurred the highest cost compare to other trades. It is recommended that the method can be extended to studying other hidden populations in the country.
\end{abstract}

Key words: Homophily, Recruits, drug users, construction sites 


\section{Introduction}

Some populations are difficult to sample (Schonlau \& Liebau, 2010), most especially the homeless, drug users and female sex workers It is not possible to construct a sampling frame of such populations as there are no registers, complete lists or a comprehensive database. There is no database of illicit drug and substance abusers in Nigeria, not even among the construction industries, and there is limited evidential guidance to effectively address the issue. Obtaining estimates of such populations in construction sites is challenging and difficult to collect as no one will want to be identified as a drug or substance user. The difficulty of estimating such populations makes them to be called the "hidden populations", "difficult to count populations" or "hard to access populations". The resulting lack of accurate, comprehensive and timely information makes evidence-based approaches to targeting prevention programs and monitoring effectiveness for such high-risk groups difficult (Salganick, Fazito, Bertoni, Abdo, Mello \& Bastos, 2011).

Three methods dominates studies of hidden populations; namely, snowball sampling, key informants sampling and targeted sampling. These methods has limitations in terms of response bias and lack of randomness, these limitations were eliminated by the invention of the respondentdriven-sampling (Heckathorn, 1997). The respondent-driven sampling is a form of a link tracing network sampling method, which is widely used to study hard-to-reach populations, this is often to estimate population proportions. RDS is used because hard-to-reach populations are characterized by the difficulty in sampling from them using standard probability methods (Gile \& Handock, 2010; Gile, 2011). Respondent-driven sampling is regarded as a potentially superior form of convenience sampling method (McCreesh, Frost, Seeley, Katongole, Tarsh, Ndunguse, et al, 2012). The process begins with a convenience sample of individuals. The key innovation is that through many waves of sampling, the dependence of the final sample on the initial convenience sample is reduced.
The Respondent-driven sampling (RDS) is based on the principle of studies on incentive system (Heckathorn, 1997). This can arise from individual-sanction-based control, where, an agent, such as teacher, parent, neighbour or AIDS prevention counselor, targets an individual for control, by promising $\mathrm{s}$ reward for a respondent undergoing an interview. It can also arise from groupmediated social control, where, respondents are rewarded not only for their participation but also for participation they elicit from a peer. In this study, both individual-sanction-based control and group-mediated social control were used.

Gile and Handock (2010) stressed that, the need for RDS is demonstrated by the recent explosion of RDS studies, both in the US and other countries, that these studies have taken place on several continents (Europe, Asia, South America, Africa, and Australia), and focused primarily on populations of injecting drug users, men who have sex with men, and sex workers. This type of study can also be used to reliably collect sensitive information about membership in a marginalized population. This is because members of the marginalized population would be underrepresented in a standard sampling frame.

RDS allowed for the breadth of coverage of network-based methods to be combined with the statistical validity of standard probability sampling methods. This makes it possible to draw statistically valid samples of unreachable groups. A mathematical model of the recruitment process then weights the sample to compensate for nonrandom recruitment patterns. This model is based on a synthesis and extension of Markov chain theory and biased network theory.

The method was developed as part of an AIDS intervention prevention project, 'the Eastern Health Connecticut Outreach (ECHO) project' which targets active injection drug users for interviews, AIDS prevention education and HIV testing and counselling (Broadhead et al, 1995; Broadhead \&Heckathorn, 1996; Heckathorn, 1997, AbdulQuader et al., 2006, Johnston, et al., 2008). Since its development, the US centres for 
disease control (CDC) uses RDS for behavioural and biological sampling among populations of intravenous drug users. RDS is a method both for data collection and statistical inference. In RDS, sampling proceeds as follows, a small number of individuals are selected in the sample. Once in the sample, participants are given a number of coupons to distribute among other persons known of the target population, inviting them to join sample, this process is repeated until a large enough sample has been obtained. Thus, RDS exploits the network of social relations connecting the target population to facilitate sampling. This strategy also reduces the confidentiality concerns generally associated with sampling from stigmatized populations.

Recruitments of participants in begins with purposive sampling of initial respondents ("seeds") from the target population. Once a seed completes the study assessment, he/she is compensated for participation ("primary incentive") and then asked to recruit a predetermined number of peers (usually 2 to 3 ) using recruitment coupons. The seed is rewarded with a "secondary incentive" if their recruit is eligible and enrolled in the study. Enrolled participants then serve as recruiters and are offered the same primary and secondary incentives. This procedure creates an expanding system of chain referrals characterized by "waves" of recruitment until the target community is saturated or the desired sample size is reached (Heckathorn, 1997; Johnston et al., 2008). The RDS requires that the 'seeds' are not to identify their recruits to the investigator, but merely to recruit them into the study which is crucial for sampling hidden populations, the recruit-recruiter relationships can be determined from the identifiers of the coupons. Estimates are therefore based on the information collected from the respondents and from the recruitment patterns. Respondents are also asked how many people they know within the population of interest, this provide an estimate of degree. The population quantity of interest is the proportion of eligible individuals. Individuals are likely to recruit members of their own group, this is called homophily. The tendency to recruits individuals from a different group is called heterophily.

\section{Material and Methods \\ The RDS Estimators of population proportion}

The RDS estimators are derived from the analysis of network structure, (Salganik \& Heckathorn, 2004; Volz \& Heckathorn, 2008), the connection between network structure and a population estimator is based on the reciprocity model. According to Tomas and Gile (2012) these estimators are either functions of Hansen-Hurwitz estimators or the Horvitz-Thompson Estimators, these include the Naiive estimator, the successive sampling estimator, the Salganik-Heckathorn estimator (Salganik \& Heckathorn, 2004), Heckathorn estimator (Heckathorn, 2007) and the VolzHeckathorn estimator (Volz \& Heckathorn, 2008). The RDSAT version 7.0 used in this work is based on the Heckathorn estimator, hence we present it here.

Heckathorn (H) Estimator: The H-estimator is an extension of the $\mathrm{SH}$-estimator and has the potential to control for biases introduced by differential recruitment and recruitments effectiveness. This estimator assumed that only one coupon, perfect recruitment effectiveness and no non-response, the sampling is treated as a Markov chain. Here, time is indexed by the wave of the sample, and the state of the chain in a given wave is the degree group of the sampled individual. Degree groups are formed by portioning the reported degrees into groups of contiguous degrees. In such systems, reciprocity also extends to ties linking the groups.

The Heckathorn estimator can be seen as the product of four parameters;

(i) $\quad N$ the population size,

$$
\begin{aligned}
N= & N_{A}+N_{B} \\
& N_{A} \text { and } N_{B} \text { are the number of }
\end{aligned}
$$
members belonging to group $A$ and $B$ respectively.

(ii) $\quad P_{A}$ and $P_{B}$ the proportion of members who belongs to group $A$ and $B$ respectively,

$$
P_{A}=\frac{N_{A}}{N}
$$


(iii) $\quad D_{A}$ and $D_{B}$ the mean degree of group $A$ and $B$ respectively,

$$
D_{A}=\frac{T_{A}}{N_{A}}
$$

Where, $T_{A}$ is the number of ties of group $A$

(iv) $\quad C_{A B}$ the proportion of cross-cutting ties

$$
C_{A B}=\frac{T_{A B}}{T_{A}}
$$

Where, $T_{A B}$ the product of these four terms, is the number of ties from $A$ to $B$ that is,

$T_{A B}=N P_{A} D_{A} C_{A B}$

Since, $N_{A}=N P_{A}, T_{A}=N_{A} D_{A}$ consequently, $T_{A B}=T_{A} C_{A B}$ it is assumed that the ties between groups $A$ and $B$ are equivalent, hence,

$$
T_{A B}=T_{B A}
$$

Mathematically, the group proportions sums to one, that is,

$P_{A}+P_{B}=1$

Thus, from (6),

$N P_{A} D_{A} C_{A B}=N P_{B} D_{B} C_{B A}$

$\Rightarrow N P_{A} D_{A} C_{A B}=N\left(1-P_{A}\right) D_{B} C_{B A}$

$\therefore P_{A}=\frac{D_{B} C_{B A}}{D_{B} C_{B A}+D_{A} C_{A B}}$

Using the nomenclature $H$ for Heckathorn the $\mathrm{H}$-estimator is now,

$$
\hat{P}_{A}^{H}=\frac{{ }_{A} \hat{D}_{B} \hat{C}_{B A}}{{ }_{A} \hat{D}_{A} \hat{C}_{A B}+{ }_{A} \hat{D}_{B} \hat{C}_{B A}}
$$

Where, ${ }_{A} \hat{D}_{A}$ and ${ }_{A} \hat{D}_{B}$ the adjusted degree estimates of group A and B respectively.

\section{Coverage, Mapping and Construction Sites Identification}

Two local governments were selected each, from Adamawa and Taraba States, these include; Adamawa: Yola North and Yola South while, Taraba: Jalingo and Zing LGA. 13 construction sites were mapped in each of the two states adding up to 26 construction sites in both states. In each of the selected sites, the construction site's managers were the key informants who recruited the initial seeds for the survey. The construction sites were selected based on the following criteria;

i. Active construction sites with personnel actively working for at least 2 years.

ii. A site manager on that site that has been working in that company for at least 2 years.

Eligibility to participate as a seed required the following inclusion criteria.

i. Being at least 18 years of age and above ii. Having lived in the locality for over a year and worked in construction sites

iii. Be a known alcoholic/drug/substance user

iv. Being in possession of the coupon

\section{Coupon Design}

In its manual about the use of RDS in detecting HIV infections, the World Health Organization, WHO (2013) recommends that coupons; should provide the information necessary for respondents to participate in the survey, should be easy to track without being easily reproducible, should contain the information needed to link the interviewee with his or her recruiters and recruits, and should have an attractive appearance indicating its value. In adhering to WHO (2013) standards and to ensure that our coupons are unique and cannot be reproduced, we created laminated white colored coupons with a unique \& identifiable identification number. The coupon had two parts, one for the interviewee and the second for the recruit. The two parts is to enable the interviewee keep track of what was kept and what was given out. The coupons had a sequential numbering system of seven figures for the initial seeds with a different last figure for each seed. Each seed was given three coupons to recruit other seeds. Figure 1 below shows the coupon used for recruiting. 


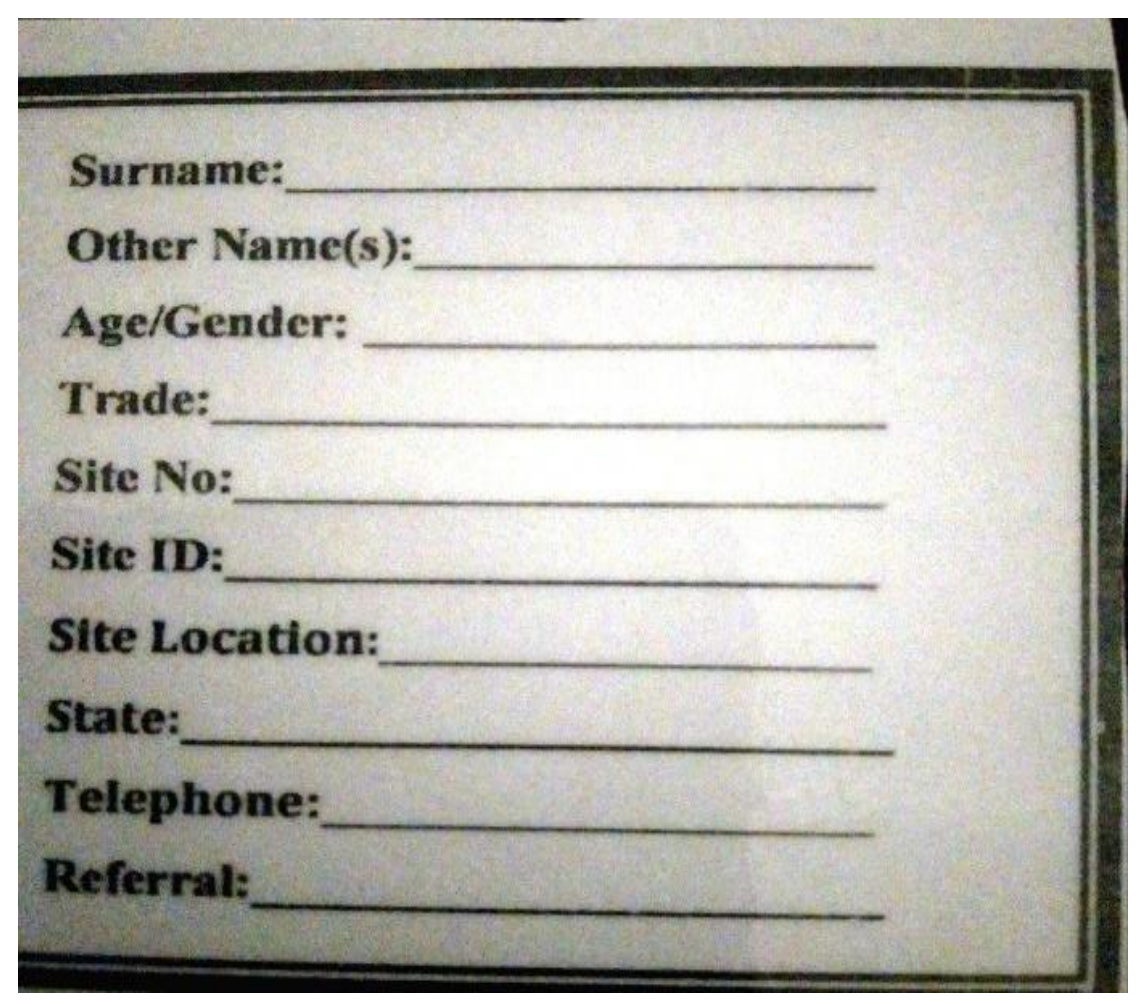

Fig. 1: Showing the coupon given to initial seeds to recruit others

The construction site workers who are known to be alcoholics/substance users were chosen purposively as the initial seeds. The 12 Participants (Recruits) received 3 coupons to give to other drug users known to them and invite them as Participants. Those first seeds who came as a result of the invitations received were interviewed, given a primary incentive of recharge card (N500) \& lunch (N200) while a secondary incentive of transportation (N1000) was provided after bringing other recruits to the program. Participants were divided into two groups; group 1 -aged 30 and below while group 2- aged above 30 . The whole recruitment process after the coupons were distributed took 21 days (workdays except on Sundays) from June $21^{\text {st }}$ to $13^{\text {th }}$ July 2019 in Adamawa State and July $21^{\text {st }}$ to August 13th in Taraba State.

\section{Results}

Respondent-Driven Sampling Analysis Tool (RDSAT) Version 7.0 designed by Spiller, Cameron andHeckarthon (2012) was used for analysis. Net draw created by Borgatti (2002) was used to graph the network recruitment chain. Overall, 660 of the recruits (including the seeds); $n=330$ from both states were given coupons to recruit others. Out of which 37 recruits who received the coupons did not return while 623 coupons were retrieved successfully. The recruitment pattern and analysis for the two states are here presented.

\section{Adamawa State recruitment pattern}

The initial seeds with their sociocharacteristics for the Adamawa state are presented in Table 1, RDS estimates are presented in Table 2, while Figure 2 shows the recruitment chain. 
Estimating the Proportion of Alcohol, Illicit Substance and Drug Users...

Table 1: Socio Characteristics of Seeds for Adamawa State

\begin{tabular}{cccccc}
\hline Seed & Survey site & Status & Age & Trades & Network size \\
\hline 1 & Site 1 & DU & 29 & Carpenter & 30 \\
2 & Site 2 & DU & 33 & Mason & 11 \\
3 & Site 3 & AC & 27 & Mason & 33 \\
4 & Site 4 & AC & 42 & Mason & 67 \\
5 & Site 5 & SU & 26 & Electrician & 34 \\
6 & Site 6 & DU & 36 & Plumber & 50 \\
7 & Site 7 & SU & 40 & Electrician & 23 \\
8 & Site 8 & AC & 23 & Tiler & 45 \\
9 & Site 9 & AC & 27 & Electrician & 67 \\
10 & Site 10 & SU & 27 & Tiler & 88 \\
11 & Site 11 & SU & 24 & Carpenter & 90 \\
12 & Site 12 & SU & 25 & Mason & 25 \\
13 & Site 13 & AC & 25 & Carpenter & 25 \\
\hline
\end{tabular}

Su-Substance user, DU-Drug user, AC-Alcohol

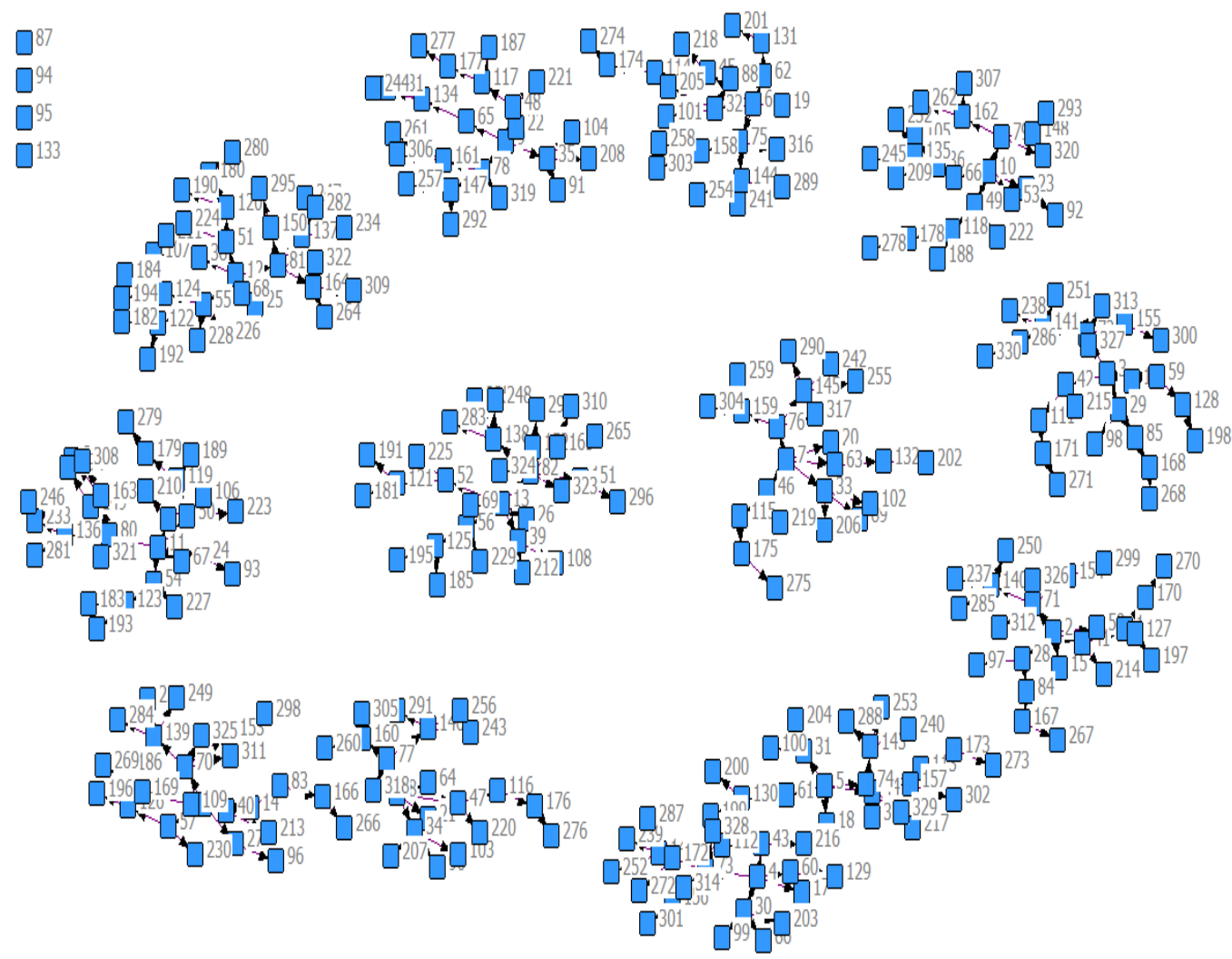

Fig. 2: Adamawa RDS recruitment chain 
Table 2: RDS Estimates for Adamawa State

\begin{tabular}{llcc}
\hline Person who recruited & \multicolumn{2}{c}{ Recruits } \\
\hline Group 1 & Group 1 & Group 2 & 309 \\
Group 2 & 294 & 15 & 4 \\
Total & 4 & 0 & $\mathbf{3 1 3}$ \\
& $\mathbf{2 9 8}$ & $\mathbf{1 5}$ & 330 \\
Sample Size & & & 13 \\
Initial Recruits & 315 & 15 & 313 \\
Total Recruits & 13 & 0 & 1.0 \\
Estimated population proportions & 298 & 15 & 1.0 \\
Sample Proportions & 0.892 & 0.108 & 1.0 \\
Recruitment proportions & 0.955 & 0.045 & 1.0 \\
Equilibrium sample distribution & 0.952 & 0.048 & 0.046 \\
Mean Network size. N (algebraic) & 0.954 & 17.533 & \\
Mean Network size. N (multiplicity) & 51.413 & 14.384 & \\
Mean Network size. N (dual component) & 36.459 & 14.314 & \\
Homophily (Hx) & 35.598 & -1.0 & \\
Affiliation Homophily (Ha) & 0.549 & -1.0 & \\
Degree Homophily (Hd) & -0.002 & -0.57 & \\
Population Weights & 0.561 & 2.37 & \\
Estimate population proportions Lower bound & 0.935 & 0.058 & \\
Estimate population proportions upper bound & 0.841 & 0.159 & \\
Adjusted Average Net Size & 0.942 & 14.384 & \\
\hline
\end{tabular}

\section{Taraba State recruitment pattern}

The initial seeds with their socio-characteristics for Taraba state are presented in Table 3, RDS estimates are presented in Table 4, while Figure 3 shows the recruitment chain.

Table 3: Socio Characteristics of Seeds for Taraba State

\begin{tabular}{lccccc}
\hline Seed & Survey site & Status & Age & Trades & Network Size \\
\hline 1. & Site 1 & DU & 33 & Carpenter & 13 \\
2. & Site 2 & DU & 33 & Carpenter & 23 \\
3. & Site 3 & SU & 29 & Carpenter & 12 \\
4. & Site 4 & SU & 22 & Mason & 15 \\
5. & Site 5 & SU & 25 & Mason & 10 \\
6. & Site 6 & SU & 33 & Plumber & 12 \\
7. & Site 7 & AC & 40 & Welder & 13 \\
8. & Site 8 & SU & 23 & Carpenter & 25 \\
9. & Site 9 & SU & 23 & Painter & 27 \\
10. & Site 10 & AC & 37 & Mason & 16 \\
11. & Site 11 & AC & 24 & Mason & 15 \\
12. & Site 12 & SU & 28 & Mason & 12 \\
13. & Site 13 & AC & 26 & Electrician & 15
\end{tabular}

SU- Substance user, DU- Drug User AC- Alcoholic 


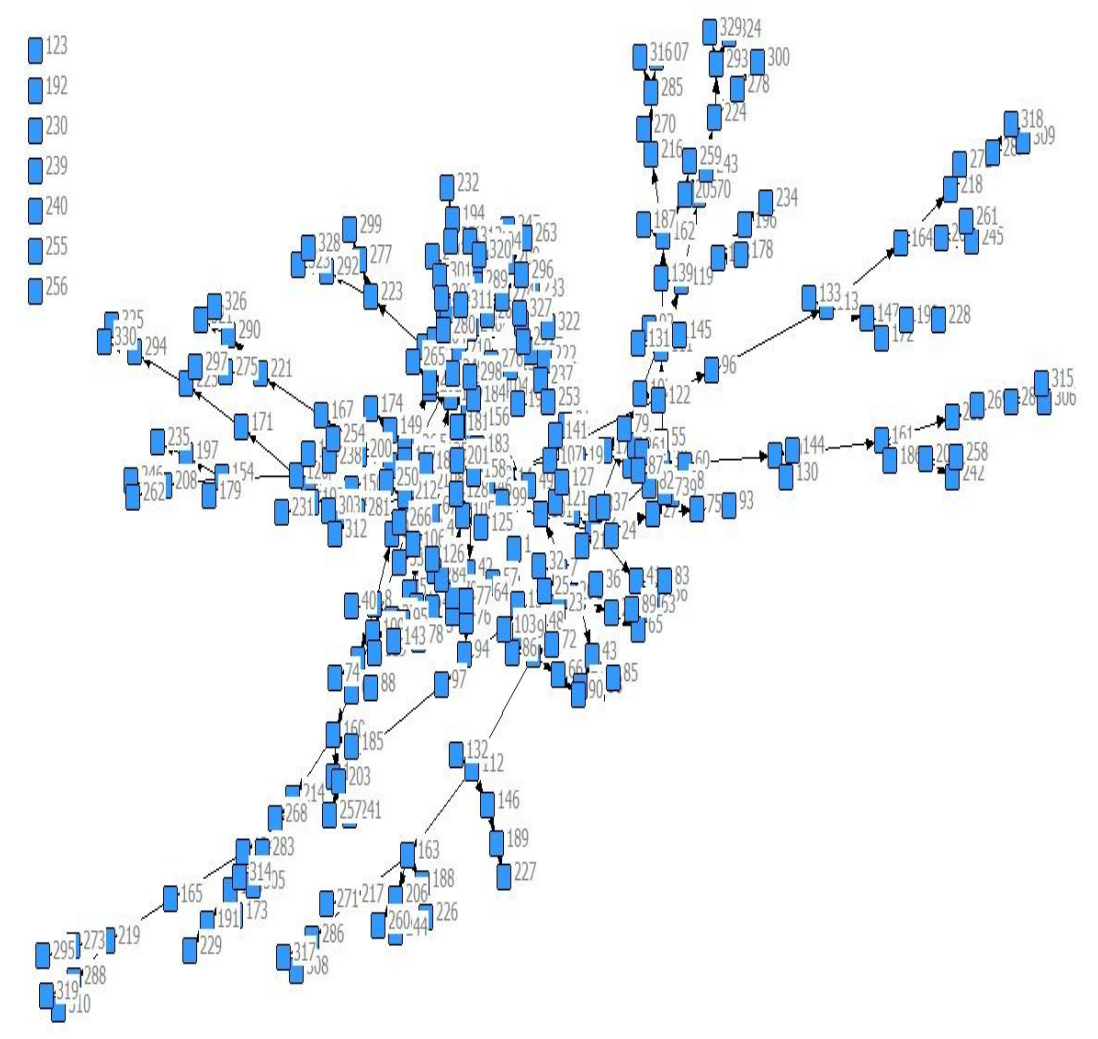

Fig. 3: Taraba State recruitment chain

Table 4: RDS Estimates for Taraba State

\begin{tabular}{|c|c|c|c|}
\hline \multirow[t]{2}{*}{ Person who recruited } & \multicolumn{2}{|c|}{ Recruits } & \multirow[t]{2}{*}{ Total } \\
\hline & Group 1 & Group 2 & \\
\hline Group 1 & 273 & 14 & 287 \\
\hline Group 2 & 24 & 0 & 24 \\
\hline Total & 297 & 14 & 311 \\
\hline Sample Size & 315 & 15 & 330 \\
\hline Initial Recruits & 18 & 1 & 19 \\
\hline Total Recruits & 297 & 14 & 311 \\
\hline Estimated population proportions & 0.954 & 0.046 & 1.0 \\
\hline Sample Proportions & 0.955 & 0.045 & 1.0 \\
\hline Recruitment proportions & 0.955 & 0.045 & 1.0 \\
\hline Equilibrium sample distribution & 0.953 & 0.047 & 1.0 \\
\hline Mean Network size. N (algebraic) & 41.481 & 42.5 & \\
\hline Mean Network size. N (multiplicity) & 31.139 & 31.296 & \\
\hline Mean Network size. $\mathrm{N}$ (dual component) & 32.007 & 32.173 & \\
\hline Homophily (Hx) & -0.003 & -1.0 & \\
\hline Affiliation Homophily (Ha) & -0.002 & -1.0 & \\
\hline Degree Homophily (Hd) & 0.0 & 0.0 & \\
\hline Population Weights & 0.999 & 1.018 & \\
\hline Estimate population proportions Lower bound & 0.925 & 0.022 & \\
\hline Estimate population proportions upper bound & 0.978 & 0.075 & \\
\hline Adjusted Average Net Size & 31.139 & 31.296 & \\
\hline
\end{tabular}


Substance Abuse Artisans and Cost of Materials Wastages on Building Sites

Data was collected on the material wastages across the two states, the cost are summarized in Table 5. The full data on the wastages and cost is presented in (Haruna, Yamusa \& Jibasen (forthcoming).

Table 5: Cost Estimate of Material Waste on Building Sites in the two state

\begin{tabular}{|c|c|c|c|c|c|c|c|}
\hline $\begin{array}{l}\text { Building } \\
\text { Sites }\end{array}$ & $\begin{array}{l}\text { Carpenters } \\
\qquad \begin{array}{c}\text { (A) } \\
\text { N'000 }\end{array}\end{array}$ & $\begin{array}{l}\text { Masons } \\
\text { (B) } \\
\text { N'000 }\end{array}$ & $\begin{array}{l}\text { Electrician } \\
\qquad \begin{array}{l}\text { (C) } \\
\text { N’000 }\end{array}\end{array}$ & $\begin{array}{l}\text { Tilers } \\
\text { (D) } \\
\text { N'000 }^{\prime}\end{array}$ & $\begin{array}{l}\text { Plumbers } \\
\qquad \begin{array}{l}\text { (E) } \\
\text { N'000 }\end{array}\end{array}$ & $\begin{array}{l}\text { Iron } \\
\text { Benders } \\
(\mathrm{F}) \\
\text { N'}^{\prime} 000 \\
\end{array}$ & $\begin{array}{c}\text { Site's } \\
\text { Total } \\
\text { Cost } \\
\text { N'000 } \\
\end{array}$ \\
\hline $\begin{array}{l}\text { Adamawa } \\
\text { state }\end{array}$ & 263.65 & 230.0 & 70.4 & 33.0 & 38.9 & 88.7 & 724.65 \\
\hline $\begin{array}{l}\text { Taraba } \\
\text { state }\end{array}$ & 260.60 & 208.9 & 68.9 & 36.2 & 35.0 & 82.9 & 692.50 \\
\hline
\end{tabular}

Source: Fieldwork (2019)

\section{Discussion}

Table 2 shows the initial recruits, sample size, total recruits, recruits by group and other estimates of the recruitments from Adamawa state. The results revealed that 294 individuals of group 1 category were recruited by individuals from that group while individuals from group 2 could not recruits from that group. Thus the homophily measure is 0.549 for group 1 and -1.0 , this shows that group 1 recruits more from members of the social stratum, while members of group 2 do not recruits from their own group. The recruitment proportion is thus, 0.952 for group 1 and 0.048 for group 2 . The sample proportion which is the naïve estimates is 0.955 for group 1 and 0.045 for group 2, while the population proportions using the $\mathrm{H}$-estimator is 0.892 for group1 and 0.108 for group 2. The long run probability distribution, otherwise called the equilibrium sample proportion is 0.954 initials group 1 and 0.046 for group 2 . The equilibrium sample proportion revealed that group 1 consist of $95.4 \%$ of the population of artisan involved in drug abuse, while group 2 controls only 4.6\%. This can also be seen in the mean network size, that group 1 has the highest mean network size using either the algebraic, multiplicity or the dual component. The degree homophily of 0.561 also shows that members of group 1 relates more in their social circle. Fig. 2, revealed that recruits with number 87 , $94,95 \& 133$ completely broken off the chain, they did not recruit any seed neither did they return for the secondary incentive.
Table 4 shows the initial recruits, sample size, total recruits, recruits by group and other estimates of the recruitments from Taraba state. The results revealed that group 1 recruited 273 individuals from group 1 category, while individuals from group 2 could not recruits from that group, but recruited 24 individuals from group 2. The total recruits stood at 311 artisans. The recruitment proportions are thus, 0.955 for group 1 and 0.045 for group 2. The sample proportions which are the naïve estimates is 0.955 for group 1 and 0.045 for group 2. The population proportions using the $\mathrm{H}$-estimator is 0.954 . The long run probability distribution, otherwise called the equilibrium sample proportion is 0 . 953 initials group 1 and 0.047 for group 2. The equilibrium sample proportion revealed that 95.3\% of artisans involved in drug/alcohol abuse are of group 1 category, while group 2 consists of only $4.7 \%$. Group 1 and 2 have approximately equal network size using. The negative homophily of $\quad-0.003$ for group 1 and -1.0 for group 2 shows that recruitment was not necessarily based on the group social strata. The degree homophily of 0.0 individuals relates randomly irrespective of their age group. Fig. 3 shows that, recruits $123,192,230,239,240,255 \& \quad 266$ are completely broken off the chain as they did not recruit any seed nor did not return for the secondary incentive. Table 5 revealed that carpenters incurred the highest wastages cost followed by masons, while tilers incurred the least cost. 


\section{Conclusion and Recommendation}

$660(100 \%)$ coupons were successfully distributed in the two states through the recruits (seeds), Out of which 623(94\%) was retrieved back while $37((6 \%)$ coupons were lost. The homophily measure for Adamawa state shows that group 1 recruits more from members of the social stratum, while members of group 2 do not recruits from their own group. For Taraba state, the negative homophily for both groups shows that recruitment was not necessarily based on the group social strata. The proportion of artisans who use illicit substance/drug/alcohol for group 1 is higher compare to group 2 for both states, this shows when fighting drug abuse more attention should be given to artisans of age below 30 years. The negative homophily is also an indication that another social classification is required for future studies. Cost of wastages in construction work revealed that Carpenters who engaged in drugs/substance/alcohol used incurred the highest cost. It is recommended that Government and policy makers should incorporate this method in studying hidden populations. Non-governmental organizations working in the north east of Nigeria can also use this method to estimate the proportion of terrorist in the region.

\section{Acknowledgement}

We acknowledge all those that made this research a success, particularly our site managers and recruits, the Director, Centre for Research and Development, Modibbo Adama University of Technology, Yola, Prof S. A. Osemeahon for effective coordination of the centre. Finally we acknowledge the Tertiary Education Trust fund (TETFUND) for sponsoring this work as part of her 2018 Institutional Based Research (IBR).

\section{References}

Abdul-Quader A.S, Heckathorn D.D., McKnight C., Bramson H., Nemeth C., Sabin, K., Gallagher K., and Des Jarlais D.C. (2006). Effectiveness of Respondent-Driven Sampling for Recruiting Drug Users in New York City: Findings from a Pilot Study. Journal of Urban Health. 83:459-476.
Borgatti, S.P. (2002); Netdraw Software for Network Visualization. Analytic Technologies: Lexington, KY

Broadhead, R.S. and Heckathorn, D.D. (1996). AIDS Prevention outreach among injection drug users: Agency Problems and new approaches. Social Problems, 41(3), 473- 495.

Broadhead, R.S,.Heckathorn, D.D., Jean P.C. Grund, L Synn Stern and Anthony, D.L. (1995): Journal of Drug Issues 25(3),531-564.

Gile, K.J. and Handock, M.S. (2010). Respondent-Driven Sampling: An Assessment of Current Methodology Sociol Methodol. 40(1): 285-327. doi:10.1111/j.1467-9531.2010.01223.x

Gile, K.J. (2011). Improved Inference for Respondent-Driven Sampling data with application to HIV prevalence estimation. Journal of the American Statistical Assoc. 106 135-146

Heckathorn , D.D. (1997). Respondent Driven Sampling: A new approach to the study of hidden populations. Social Problems. 44(2) 174-199.

Heckathorn, D.D. (2002). Respondent-driven sampling II: deriving valid population estimates from chain referral samples of hidden populations. Social Problems 49 (1):11-34.

Heckathorn D.D. (2007). Extensions of Respondent-Driven Sampling:Analyzing Continuous Variables and Controlling for Differential Recruitment. Sociological Methodology. 37:151-207.

Johnston L.G, Malekinejad M., Kendall C., Iuppa I.M, and Rutherford G.W. (2008). Implementation Challenges to Using Respondent-Driven Sampling Methodology for HIV Biological and Behavioral Surveillance: Field Experiences in International Settings. AIDS and Behavior. 2008;12:131-141.

McCreesh, N, Frost, S.D.W., Seeley, J., Katongole, J., Tarsh, M.N., Ndunguse, et al., (2012)Evaluation of Respondentdriven Sampling. Epidemiology: 23(1) 138-147 doi:10.1097/EDE.0b013e3182 $3 \mathrm{ac} 17 \mathrm{c}$ 
Salganick, M.J. Fazito, D., Bertoni, N., Abdo, A.H., Mello, M.B. and Bastos, F.I. (2011). Assessing network scale-up estimates for groups most at risk of HIV/AIDS: evidence from multiple study of heavy drug users in Curitiba, Brazil, American Journal of Epidemiology 174(10) 1190-1196

Salganik M.J, and Heckathorn D.D (2004). Sampling and Estimation in Hidden Populations Using Respondent-Driven Sampling. Sociological Methodology. 34:193-239
Schonlau, M. and Liebau, E. (2010). Respondent Driven Sampling. DIW Berlin Discussion paper No.1048 Berlin, German Institute of Economic Research.

Spiller, M.W., Cameron, C., Heckathorn, D.D. (2012); Respondent-Driven Sampling Analysis Tool (RDSAT) Version 7.0

Volz E, and Heckathorn D.D (2008). Probability Based Estimation Theory for Respondent Driven Sampling. Journal of Official Statistics. 24:79-97

World Health Organization (2013). Manual on Driven-respondent sampling 